\title{
CARDIAC RESUSCITATION
}

\section{Therapeutic hypothermia after out-of-hospital cardiac arrest}

Guidelines recommend therapeutic hypothermia be initiated soon after hospital arrival in patients who have been resuscitated after cardiac arrest, but are still comatose, to help protect the patient's brain from injury. Two trials presented at the 2013 AHA Scientific Sessions were designed to shed light on the optimal target temperature for this therapeutic hypothermia, and whether the initiation of body-temperature lowering before hospital arrival is of additional benefit to the resuscitated patient.

Presenting the TTM trial investigators' findings at the AHA meeting, Niklas Nielsen explained that "hypothermia to $32-34^{\circ} \mathrm{C}$ after out-of-hospital cardiac arrest

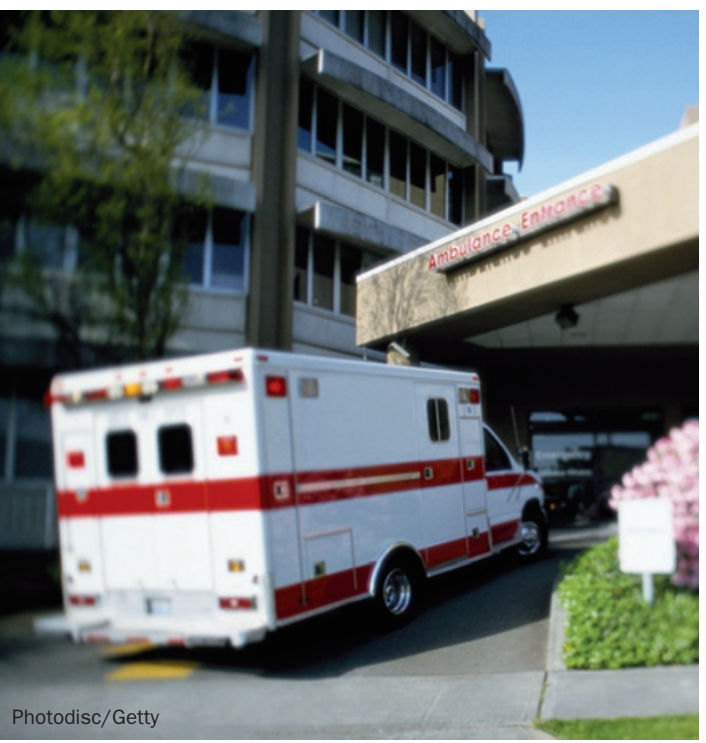

is recommended in guidelines globally". The TTM trial investigators reassessed the evidence for this recommendation in detail, however, and concluded that the optimal temperature target has not yet been determined in humans. They, therefore, set out to compare hypothermia to a target of $33^{\circ} \mathrm{C}$ with a target of $36^{\circ} \mathrm{C}$ in a randomized trial involving 950 patients.

All-cause mortality did not differ significantly between the $33^{\circ} \mathrm{C}$ and $36^{\circ} \mathrm{C}$ groups, nor did neurological outcomes or the total rates of serious adverse events. However, hypokalaemia occurred more often in the patients with the lower temperature target. The TTM trial investigators point out that, although targeting body temperature to $33^{\circ} \mathrm{C}$ did not confer any benefit over a $36^{\circ} \mathrm{C}$ target in their trial, "it is important to acknowledge that there may be a clinically relevant benefit of controlling the body temperature at $36^{\circ} \mathrm{C}$, instead of allowing fever to develop". Benjamin Abella, an independent commentator on the trial, agreed with this point and stressed at the AHA meeting that the TTM trial "was not a reappraisal of whether or not targeted temperature management could help patients following cardiac arrest, but indeed was looking at two different doses of targeted temperature management". Abella hopes that the medical community bears in mind that " $36^{\circ} \mathrm{C}$ really is indeed a managed temperature with the avoidance of fever." He also hypothesizes that there might still be a patient group in whom a target temperature of $33^{\circ} \mathrm{C}$ is valid and calls for more research in this area.

The second trial tested whether prehospital cooling via paramedic intravenous administration of cold saline conferred any additional benefit in patients resuscitated after cardiac arrest. Despite having a $>1{ }^{\circ} \mathrm{C}$ lower mean core body temperature on arrival at hospital, no mortality or neurological benefit was noted in patients with or without ventricular fibrillation who underwent prehospital cooling. Compared with the controls, however, the patients who underwent prehospital cooling had higher rates of rearrest in the field, diuretic use, and pulmonary oedema on their first chest $\mathrm{X}$-ray (which resolved within $24 \mathrm{~h}$ of admission). Acting as discussant for the trial presentation at the AHA meeting, Maaret Castrén explained that the administration of cold fluids can result in decreased coronary perfusion pressure, which is not beneficial to the patient. She points out, therefore, that "this method might not be the optimal one to use in the prehospital setting."

Bryony M. Mearns

Original articles Nielsen, N. et al. Targeted temperature management at $33^{\circ} \mathrm{C}$ versus $36^{\circ} \mathrm{C}$ after cardiac arrest. N. Engl. J. Med. doi:10.1056/NEJMoa1310519 | Kim, F. et al. Effect of prehospital induction of mild hypothermia on survival and neurological status among adults with cardiac arrest: a randomized clinical trial. JAMA doi:10.1001/ jama.2013.282173 